\title{
Moisture Characteristics of Hanford Gravels: Bulk, Grain-surface, and Intragranular Components
}

\author{
Tetsu K. Tokunaga, Keith R. Olson, and Jiamin Wan
}

\begin{abstract}
Although gravels comprise large portions of some vadose zones, their unsaturated hydraulic properties have received relatively little attention. This study examines moisture retention relations in the 2 and $6 \mathrm{~mm}$ size fractions of gravels from the Hanford formation vadose zone (Washington State). Understanding flow and transport within this formation is important because parts of it have become contaminated by leakage of radioactive wastes. Moisture retention relations were obtained over a very wide energy range, with attention to water retained in intragranular pores and along grain surfaces. External surfaces of these gravels have root meansquare roughnesses in the $\mu \mathrm{m}$ range, with sparsely distributed deep (hundreds of $\mu \mathrm{m}$ ) pits. Water films on these external surfaces are volumetrically insignificant at matric potentials less than about $-2 \mathrm{kPa}$. "Residual" water in these gravels occurs in intragranular pores, accounts for about $10 \%$ of the total porosity, and is effectively hydraulically immobile. The intragranular domain in Hanford gravels also has a large specific surface area of about $11 \mathrm{~m}^{2} \mathrm{~g}^{-1}$. Thus, exchanges of solutes (including contaminants) between the intragranular domain of Hanford gravels and their immediate surrounding are significant and diffusion-limited.
\end{abstract}

\section{Introduction}

Gravels can make up large fractions of the subsurface, including vadose zones. The extensiveness of some gravel deposits is evident from the fact that they serve as major aquifers that supply groundwater for agricultural, industrial, and municipal use. Some gravel deposits are mined for use in construction. Because some gravel deposits do occur in the vadose zone, understanding unsaturated flow and transport in such settings requires knowledge of their hydraulic properties. Some gravel deposits occur in heavily contaminated vadose zones such as the Hanford Site (Washington State) where radioactive wastes have leaked. Gravels are also an important component in engineered capillary barriers for subsurface waste isolation (Ross, 1990; Selker, 1997). However, relatively little information is available on the unsaturated hydraulic properties of gravels. Measurements of moisture characteristics on gravels have been reported by Miyazuki (1988), Khaleel and Relyea (1997), Conca et al., (1998), and Tokunaga et al. (2002). Unsaturated hydraulic conductivities of gravels have been reported by Miller and Bunger (1963), Conca et al., (1998), and Khaleel and Relyea (2001).

Because of their large size, water retention in unsaturated gravels must be mainly associated with grains rather than with the macroscopic pore network. Thus, water retention depends on intragranular and grain surface morphology. We suggest several possible basic grain morphologies depicted in Fig. 1 for cross-sections through rounded grains. Analogous varieties exist for angular grains. The simplest representation is that of a smooth-surface ellipsoid of revolution, with negligible intragranular porosity. Other possibilities include rough-surface grains, and varying importance of internal porosity, as well as possible additional weatheringinduced near-surface alterations.

Whether crystalline or amorphous, the larger grain-size of gravels offers the potential for significant intragranular porosity and intragranular surface area. Diffusion coefficients within this intragranular domain can be very low because of constrictive and tortuous pathways of 
microporous networks of boundaries between microcrystals, and because of low porosity. Diffusive transport times within grains scale with the square of the diameter, such that equilibration times within $4 \mathrm{~mm}$ gravel will be 400 times longer than in $200 \mu \mathrm{m}$ fine sand of otherwise equal nature. Potassium ion diffusion coefficients ranging from $2.2 \times 10^{-14}$ to $1.7 \times 10^{-11}$ $\mathrm{m}^{2} \mathrm{~s}^{-1}$ were measured in a variety of gravels by Conca and Wright (1990). Thus, porous gravels can behave as sources and sinks of solutes, including contaminants, with slow exchange times. Water retained in intragranular pores will likewise exchange with the surrounding environment only over long times, thus behave hydraulically as "residual moisture". The $\mathrm{K}_{\mathrm{d}}$ values measured by Kaplan et al. (2000) for $\mathrm{Sr}^{2+}$ equilibration provided strong evidence for significant amounts of intragranular surface in Hanford gravels. The $\mathrm{K}_{\mathrm{d}}$ values in their gravels were about $50 \%$ that of the $<2 \mathrm{~mm}$ size fraction, hence still quite significant, and much greater than expected from external surface area alone.

The external surfaces of gravels can also be important since their unsaturated hydraulic properties can be strongly influenced by water films coating grain surfaces. Grain surface wettability and microtopography are then important in controlling water film hydraulic relations. The various possible configurations illustrated in Fig. 1 suggest that the unsaturated hydraulic properties of gravels can be quite diverse. Measurements of intragranular and surface characteristics will help identify which of the characteristics illustrated in Fig. 1 apply to specific types of gravels.

In a recent study on Hanford formation gravels, large saturation changes occurring within the near-zero matric potential region were reported (Tokunaga et al., 2002). Since that study was restricted to a narrow energy range, an understanding of the nature of "residual" saturation remained to be developed. This was especially warranted because the levels of residual saturation were relatively high, being in the range of 0.1 to 0.2 . Thus, the present work addresses a much broader range of potentials and saturations in Hanford gravels, utilizing suction plate, pressure plate, and vapor pressure methods to characterize samples. Water vapor adsorptiondesorption measurements were obtained in order to test the hypothesis that the intragranular porosity of these gravels is substantial.

In addition to these bulk measurements, external grain surface properties were characterized microscopically (laser profilometry, atomic force microscopy, and scanning electron microscopy) and hydraulically (surface water film measurements at controlled matric potentials). We define the gravel grain surface moisture characteristic as the relation between the average (external surface) water film thickness and the matric potential (Tokunaga and Wan, 1997). The grain surface moisture characteristic is the surface analog of the familiar volumetric moisture characteristic relation. This relation is important to quantify because it can strongly influence unsaturated flow and transport in open framework (well-sorted, with minor fine fraction) gravels.

\section{MATERIALS AND METHODS Gravels}

Gravel samples were obtained from the Hanford Site in south-central Washington State. The Hanford formation gravels and sandy gravels were deposited during cataclysmic floods released from Pleistocene ice-dammed lakes. Our samples were excavated from Site 218-E-12B, in the north-east corner of the 200-East Area. In the present study, we report primarily on the 2.0 to $2.4 \mathrm{~mm}$ and the 5.6 to $6.3 \mathrm{~mm}$ size fractions, referred to here as 2 and $6 \mathrm{~mm}$ Hanford gravels, respectively. As shown later, the Hanford gravels have significant intragranular porosity and 
surface area. In order to obtain comparisons with gravels that have less intragranular influences, additional samples were obtained from deposits along the Maurice River, New Jersey. These gravels are primarily quartz ( 98 to $99 \%$ ). The 2.0 to $2.4 \mathrm{~mm}$ and the 8.0 to $9.5 \mathrm{~mm}$ size fractions of these gravels were only used in a few water vapor sorption measurements, and will be referred to as 2 and $9 \mathrm{~mm}$ quartz gravel, respectively. The overall shapes of the Hanford and quartz gravels were similar, with both having sphericities of about 0.7 and roundness of about 0.6 (Krumbein and Sloss, 1966).

\section{Intragranular properties}

Water vapor adsorption and desorption isotherms were measured on Hanford and quartz gravels in order to characterize moisture retention at low (very negative) water potentials and to obtain estimates of specific surface area. The oven-dry $\left(110^{\circ} \mathrm{C}, 24 \mathrm{~h}\right)$ Hanford sample masses were about $34 \mathrm{~g}$ and $66 \mathrm{~g}$ for the $2 \mathrm{~mm}$ and $6 \mathrm{~mm}$ fractions, respectively. The 2 and $9 \mathrm{~mm}$ fractions of the quartz gravel were tested in nominally $80 \mathrm{~g}$ samples. The initial motivation for testing 2 different size fractions was based on the assumption that the measurements would be strongly correlated to external surface area, hence water retention would be inversely proportional to the grain-size. Large sample masses were used to partially compensate for the lower specific external surface area. After oven-drying and cooling to room temperature, samples were placed into weighing jars and equilibrated over (aqueous) saturated salt solutions (Table 1) kept in a controlled temperature $\left(25^{\circ} \pm 0.5^{\circ} \mathrm{C}\right)$ incubator. These salt solutions provided controlled relative humidities, $R H$, ranging from 0.07 to 0.97 , and water potentials from -364 to $-4.6 \mathrm{MPa}$. The $R H$ is the ratio between the water vapor pressure and the saturation vapor pressure $(3.17 \mathrm{kPa}$ at $25^{\circ} \mathrm{C}$ ). The quartz gravels were tested only up to a $R H=0.33$ because only adsorption in the low $R H$ range can be used to infer surface areas, and because the moisture characteristics of these gravels were beyond the scope of this study. The jars containing gravel samples were periodically removed from constant humidity chambers and weighed to monitor progression towards adsorption equilibrium. Vapor adsorption equilibrium was reached in 10 to 20 days, after which gravels were again oven-dried. For desorption isotherms, gravel samples were immersed in water overnight, quickly drained, placed into weighing jars, and equilibrated at controlled $R H$ with the same saturated salt solutions. Desorption equilibrium was reached in about 30 days for all samples except those in the chamber with $R H=0.967$. These latter samples exhibited very slow drying, because of weak vapor pressure gradients acting between the gravels and salt solution reservoir.

Estimates of surface areas were obtained in two ways. In the first approach, water vapor adsorption data obtained with $R H$ less than 0.30 were used in the BET (Brunauer, Emmett, and Teller, 1938) method to calculate surface areas. This approach amounted to applying the standard BET analysis briefly described later, but with water as the adsorbate. Conventional surface area measurements were also obtained on these samples by BET analyses using $\mathrm{Kr}$ and $\mathrm{N}_{2}$ adsorbates (Micromeretics, Norcross, GA).

\section{Bulk gravel moisture characteristics}

Moisture characteristics were only obtained for the Hanford gravel. The determination of moisture characteristic relations for gravels presents an experimental challenge because significant changes in saturation occur over matric head intervals that are shorter than typical column heights. At matric potentials close to zero, the upper portion of an equilibrium gravel column can be significantly less saturated than the bottom portion. Methods to obtain correct 
saturation-potential relations under these conditions have been presented by Dane et al. (1992), Liu and Dane (1995), Schroth et al. (1996), Jalbert and Dane (2001), and Tokunaga et al. (2002). The suction plate approach described in Tokunaga et al. (2002) was used in this present work, with gravel packed to a height of $30 \mathrm{~mm}$ in large ( $82.6 \mathrm{~mm}$ ID), modified Tempe cells. Boundary matric potentials were controlled to within $\pm 15 \mathrm{~Pa}$ in this region of the drainage curve. Measurements at lower (more negative) matric potentials were obtained using the pressure plate method (Dane and Hopmans, 2002), with 2-stage pressure regulation (final regulated potentials controlled to within $\pm 100 \mathrm{~Pa}$ ), and with a $0.5 \mathrm{bar}$, high-flow plate (Soilmoisture Equipment Corp., Goleta, CA).

\section{External grain surface properties}

In order to evaluate the role of external grains surfaces on water retention, measurements were made to characterize grain surface topography, and to quantify the relation between average water film thickness and matric potential. Grain surface topography was characterized using a laser profilometer (UMB, Sunnyvale, CA) and an atomic force microscope (AFM, Park Scientific Autoprobe M5, Veeco Instruments, Woodbury, NY) as previously described (Tokunaga et al., 2000; Wan and Tokunaga, 2000). A scanning electron microscope was used to obtain images of gravel grain surfaces.

Grain surface moisture characteristics could in principle be obtained through very accurately determine adsorption isotherms and moisture characteristic measurements on bulk sediments, combined with information (or assumptions) on moisture within intragranular pores and in pendular rings. Instead, we chose to obtain average film thickness measurements directly at various points on a single grain surface. Microscopic inspection of external surfaces of 1 to 30 $\mathrm{mm}$ grain-sizes of Hanford gravels did not reveal any size-dependent topography, thus measurements on a single grain are expected to be representative of other grain-sizes. Using a presaturated single grain provided the advantage of effectively constant grain matrix saturation, and avoiding the complicating influence of pendular rings. The method used to determine areaaveraged film thickness is based on synchrotron $\mathrm{x}$-ray fluorescence of a nonreactive tracer (selenium(VI) as $\mathrm{SeO}_{4}{ }^{2-}$, which does not undergo reduction because the system is kept equilibrated with atmospheric oxygen) dissolved in the aqueous phase, with the matric potential regulated by a modified suction plate device (Tokunaga et al., 2000). This method, previously tested on roughened quartz glass surfaces, was used on a $13 \mathrm{~mm}$ Hanford gravel specimen with its bottom surface cut flat to provide good hydraulic contact with the underlying porous plate. The x-ray microprobe beamline X26A at the National Synchrotron Light Source was used to obtain these measurements.

\section{RESULTS AND DISCUSSION Intragranular properties}

The 2 and $6 \mathrm{~mm}$ Hanford gravels had similar water vapor sorption-desorption isotherms, with both grain-sizes retaining substantial mass fractions of water (Fig. 2). In contrast, the quartz gravels had low water contents, barely at the limit of quantification $\left(\approx 0.0002 \mathrm{~g} \mathrm{~g}^{-1}\right)$. These results provide evidence for significant intragranular porosity and intragranular surface area in Hanford gravels for 2 general reasons. Firstly, the water contents are far too large to have been associated solely with films on external surfaces of solid (nonporous) grains and pendular rings in equilibrium with very low water potentials. A uniform water film coating a solid (nonporous) spherical grain of diameter $D$ has a thickness $f$ of 


$$
f=\frac{\rho_{s} D w}{6 \rho_{w}}
$$

where $w$ is the water:solid mass ratio, and $\rho_{s}$ and $\rho_{w}$ are the densities of the solid and water, respectively. This estimate leads to hypothetical film thicknesses ranging from 10 to $60 \mu \mathrm{m}$, over the matric potential range where water actually occurs in monomolecular to several molecular layer films (i.e., $\mathrm{nm}$ films). We show later that external surface roughness, although significant, cannot reconcile this approximately $10^{4}$-fold discrepancy in hypothetical film thickness. Water retention in pendular rings (Fig. 3) also cannot account for much of this discrepancy since the energy range under consideration is associated with radii of curvature $r$ less than $5 \mathrm{~nm}$, based on the Kelvin equation

$$
r=\frac{M \sigma}{\rho_{w} R T \ln (R H)}
$$

where $M$ is the molecular weight of water $\left(18.0 \mathrm{~g} \mathrm{~mol}^{-1}\right), \sigma$ is the air-water surface tension $(7.3$ $\left.\mathrm{x} 10^{-2} \mathrm{~N} \mathrm{~m}^{-1}\right), R$ is the gas constant $\left(8.314 \mathrm{~J} \mathrm{~K}^{-1} \mathrm{~mol}^{-1}\right)$, and $T$ is the temperature $(298 \mathrm{~K})$. The factor of 2 appears in the numerator for the familiar case of hemispherical and spherical interfaces, but was removed in Eq.[2] since the concave radius of curvature bridging grains $(r$ in Eq.[2] is designated $r_{l}$ in Fig. 3) is much smaller than the convex radius of curvature that circumscribes the axis between grains ( $r_{2}$ in Fig. 3). Since the Laplace relation involves sums of inverse radii, the much larger radius has only minor influence. Whether or not the Kelvin equation is valid at $r<5 \mathrm{~nm}$, and whether or not the macroscopic value of $\sigma$ is appropriate at this scale are outside the scope of this study. However, it is worth noting that Fisher and Israelachvili (1979) demonstrated applicability of the Kelvin equation down to $r=4 \mathrm{~nm}$ for cyclohexane wetting mica (with its macroscopic $\sigma$ ).

The second reason why these macroscopic results suggest substantial intragranular water retention becomes evident upon considering the fact that practically identical isotherms were obtained for the 2 and $6 \mathrm{~mm}$ Hanford gravels. If only external grain surfaces were responsible for water retention, then the $2 \mathrm{~mm}$ gravel should have 3 times greater water contents than the $6 \mathrm{~mm}$ gravel, at any given potential. This scaling of surface area per unit volume, also implicit in Eq. [1], is not supported by the data.

Calculations of effective surface areas can lead to a better understanding of residual or immobile water in the Hanford gravels. Two approaches were taken, both relying on BET calculations (Brunauer et al., 1938). In the first approach, data from the water vapor sorption isotherms were expressed in terms of the BET variable

$$
B=\frac{R H}{w(1-R H)}
$$

When $B$ is linear with respect to $R H$ (up to $R H \approx 0.3$ ), multilayer adsorption conforms to the BET model. Such conformity was obtained with our measurements on Hanford gravels (Fig. 4). The value of $w$ associated with monomolecular coverage is obtained from the inverse of the sum of the slope and intercept of $B(R H)$. This monolayer $w$ was combined with the effective area of 
water molecules, $0.106 \mathrm{~nm}^{2}$ per molecule (Gregg and Sing, 1982), to obtain the water-based specific surface area measurements of 27 and $22 \mathrm{~m}^{2} \mathrm{~g}^{-1}$ for the 2 and $6 \mathrm{~mm}$ gravels, respectively. Measurements obtained using less reactive gases $\left(\mathrm{N}_{2}\right.$ and $\mathrm{Kr}$ ) yielded specific surface areas of 11.7 and $11.3 \mathrm{~m}^{2} \mathrm{~g}^{-1}$ for the 2 and $6 \mathrm{~mm}$ gravels, respectively. It is also worth mentioning that $\mathrm{N}_{2}$ BET measurements of the $<2 \mathrm{~mm}$ (median grain-size $\approx 500 \mu \mathrm{m}$ ) fraction from the Hanford formation yielded a value of $15.5 \mathrm{~m}^{2} \mathrm{~g}^{-1}$, i.e., not much greater than the gravel fraction. All of these surface area values are large, and in the range of values for kaolinite, a low surface area clay. Measurements using water as the adsorbate commonly do yield higher BET specific surface areas than $\mathrm{N}_{2}$ and $\mathrm{Kr}$-based measurements, with differences attributed to solvation of adsorbed ions and hydration reactions (Quirk, 1955; Gregg and Sing, 1982). Differences in values obtained with different adsorbates further reflect the operationally dependent nature of specific surface area measurements (Sposito, 1984). Nevertheless, the collective evidence obtained from measurements of water uptake at low potentials indicates that the Hanford gravels have very significant internal surface area. Such high intragranular surface areas combined with large grain-sizes are expected to cause strongly diffusion-limited water and solute exchange.

\section{Bulk gravel moisture characteristics}

Drainage curves obtained on the 2 and $6 \mathrm{~mm}$ Hanford gravels are shown in Fig. 5. The near-zero matric potential region (region c in Fig. 5) within which large decreases in saturation accompanied small energy decreases is gravity-corrected for variable saturation within individual equilibrium states (Tokunaga et al., 2002). The intermediate potential range results obtained with a pressure plate are shown in region b of Fig. 5. The lowest energy range (region a in Fig. 5) is based on the previously described water vapor adsorption isotherms. The water potentials obtained in the regulated relative humidity chambers were assumed to be approximately equal to matric potentials for this purpose. This amounts to assuming that the water potential equals the matric potential plus an additive but insignificant solute potential. This assumption is justified in nearly all of these vapor pressure equilibrations since the highest water contents obtained by vapor adsorption (region a in Fig. 5) are about equal to the lowest water contents obtained with the pressure plate (region $\mathrm{b}$ of Fig. 5 ). The solute potential at this water content (saturation $\approx 0.1$ ) has a magnitude of about $-10^{5} \mathrm{~Pa}$ (estimated from measured major ion concentrations in Hanford pore water, and the van't Hoff relation). Thus, the solute potential contributes only about $2 \%$ to the highest water potential imposed by vapor pressure regulation $\left(-4.6 \times 10^{6} \mathrm{~Pa}\right.$ in Table 1$)$. Furthermore, when the saturation is reduced to 0.05 , the solute potential is about $-2 \times 10^{5} \mathrm{~Pa}$ (assuming linearity), or about $0.1 \%$ of the corresponding water potential of $-2 \times 10^{8} \mathrm{~Pa}$ (Fig. 5). Three main features of Hanford gravel moisture characteristics are evident from these results. First, practically all of the saturation changes occur within 1 to $2 \mathrm{kPa}$ of zero matric potential. Changes in saturation within this near-zero potential region are large enough that gravitycorrections were required for the $6 \mathrm{~mm}$ gravel. Gravity-corrections for the $2 \mathrm{~mm}$ gravel drainage curve are minor (Tokunaga et al, 2002). Second, the fairly high "residual saturation" region spans a very broad energy range and associated with intragranular porosity (as discussed in the previous section). Intragranular moisture retention within gravel fractions in soils have been reported previously (e.g., Montagne et al., 1992; Brouwer and Anderson, 2000), and on tuff gravel by Conca et al. (1998). The results presented in Fig. 5 show that moisture capacities (the change in saturation per unit change in matric potential) for these gravels are very low. At most, there is only about $5 \%$ change in saturation over the interval from $-1 \mathrm{kPa}$ to $-10 \mathrm{MPa}$. Third, within this broad residual saturation region, the 2 and $6 \mathrm{~mm}$ gravel curves are practically the 
same. This too results from water being retained primarily in intragranular pores, so that retention scales with bulk density rather than with external grain surface area. The nearly identical residual saturations for the 2 grain-sizes also indicate that even if present, weathering rinds have no measurable impact on moisture retention. Referring to Fig. 1, these results support morphologies $b$ and e are supported for the Hanford gravels.

\section{Grain surface properties}

The microtopography of grain surfaces reflect the combined influences of parent rock structure and weathering. In the case of Hanford gravels, many of these grains are basalt in origin, and have been mechanically weathered through glacial-fluvial processes. Thus, the vesicular imprint from trapped gas bubbles in the basalt remains, as shown in the photographs of the external surface and intragranular domain (Fig. 6). Together with the previously described results, we conclude that the Hanford gravels are represented by morphology depicted in Fig. 1e. Scanning electron micrographs of the external grain surface qualitatively show surface roughness over a range of scales (Fig. 7). Note that the surface pits, originally vesicles in the bulk basalt rock, are isolated and substantially deeper than the more pervasive roughness features. Isolated pits are typically in the range of 100 to $400 \mu \mathrm{m}$ in depth, whereas the majority of the external surface roughness is about 2 orders of magnitude finer. The latter was quantified at intermediate scale (several hundred $\mu \mathrm{m}$ traverses, with $0.1 \mu \mathrm{m}$ vertical resolution) through laser profilometry, with typical profiles shown in Fig. 8. Note that the vertical scale on this figure is expanded by a factor of 3 . The root mean-squared roughness (rmsr) at this scale is about $2 \mu \mathrm{m}$. AFM scans were difficult to obtain because of large-scale topography sometimes exceeded the instruments working range $(8 \mu \mathrm{m})$. Nevertheless, some small areas (45 to $900 \mu \mathrm{m}^{2}$ ) were scanned successfully, with typical rmsr values in the range of 0.19 to $1.92 \mu \mathrm{m}$. The average rmsr obtained from 22 area scans was $0.83 \mu \mathrm{m}$. Typical AFM surface profiles are shown in Fig. 9. The greater rmsr value obtained on the laser profiles likely resulted from scale dependence of surface roughness, increasing with measurement length or area. Rock fracture surfaces have been shown to exhibit scale-dependent roughness by Brown and Scholz (1985). In the case of granular materials, the overall curvature of the surface itself imparts greater apparent roughness with increased measurement scale, even on an ideally smooth surface, since greater elevation variations are encompassed. The AFM average rmsr of $0.83 \mu \mathrm{m}$ is a good indicator of the local topographic constraint on water film thickness since it was obtained over distances ranging from 7 to $30 \mu \mathrm{m}$. Greater distances typically intercept major ridges and pits that support only very thin (nm) and very thick (up to hundreds of $\mu \mathrm{m}$ ) "films", respectively.

Grain surface moisture characteristics were obtained at 8 randomly selected spots on the gravel sample over the matric potential range of -0.1 to $-6.1 \mathrm{kPa}\left(-10\right.$ to $\left.-620 \mathrm{~mm} \mathrm{H}_{2} \mathrm{O}\right)$. Representative drainage and wetting curves are shown in Fig. 10. Although there is some apparent variability, three main features are evident. First, very high values of average film thickness $(7$ to $10 \mu \mathrm{m})$ were obtained at very near-zero (-50 to $-100 \mathrm{~Pa})$ matric potentials. These high values of average film thickness result from filling isolated pits in the near-zero potential limit. Such pits are practically empty at lower potentials because of their large cross-sections and shallow depths. Second, average film thicknesses are equal to or less than the quantification limit of $0.3 \mu \mathrm{m}$ at matric potentials less than about $-2 \mathrm{kPa}$. This result supports the argument that moisture retention at even lower energies (pressure plate and vapor pressure controlled measurements) largely occurs in the intragranular domain. Even when the film thickness is $1 \mu \mathrm{m}$, the gravimetric water content associated with such a coating on the exterior of a $2 \mathrm{~mm}$ diameter 
grain is only about $10^{-3} \mathrm{~g} \mathrm{~g}^{-1}$ (from Eq.[1]). The third feature shown in these results is that surface film moisture characteristics do not exhibit hysteresis. This lack of hysteresis in film characteristics was demonstrated previously on a fractured rock surface (Tokunaga and Wan, 1997).

Qualitative aspects of film flow along external surfaces of Hanford gravel can be deduced from measurements just described. Film transmissivity, the unit gradient flux per surface length transverse to the flow direction, depends on surface topography and matric potential (Tokunaga and Wan, 1997). Since the vesicular pits are sparsely distributed rather than interconnected (Figs. 6 and 7), these deep surface features do not contribute significantly to film flow. Recall that the grain surfaces have been smoothed by glacial and fluvial weathering, resulting in rmsr values in the range of $1 \mu \mathrm{m}$. Under finite matric potentials, such smooth surfaces cannot support thick (e.g., $>2 \mu \mathrm{m}$ ) water films. Therefore, fast, unsaturated flow is not possible in these gravels below the matric potential at which pendular rings are no longer interconnected, since water films then control flow (Wan and Tokunaga, 1997).

\section{CONCLUSIONS}

Various techniques were used to quantify moisture characteristics of the 2 and $6 \mathrm{~mm}$ fractions of Hanford gravels. Differences between moisture characteristics for these two grainsize fractions were only important in the near-zero matric potential region associated with drainage of the primary pore network. Over a broad range of matric potentials, water content remains practically unchanged, and nearly identical for the two grain-sizes. Water retention in this range is associated with intragranular pores, and amounts to about $10 \%$ of the total porosity. The specific surface area of these gravels is fairly high (about $11 \mathrm{~m}^{2} \mathrm{~g}^{-1}$ ), and largely associated with the intragranular domain. The combination of large grain-size, significant intragranular porosity, and significant intragranular surface area make these gravels sinks and sources for solutes, with potentially long, diffusion-limited equilibration times. External grain surfaces have rmsr of about $1 \mu \mathrm{m}$ over most locations, with isolated deep pits. Such surface topography does not support thick water films at matric potentials less than about $-1 \mathrm{kPa}$, and therefore will not support fast film flow at lower energies. Although measurements were done on specific size fractions of Hanford gravels, the conclusions concerning the intragranular domain and grainsurface characteristics remain valid for these gravels in well-graded mixtures of grain-size.

\section{ACKNOWLEDGMENTS}

We thank Andrew Mei, Eduardo Saiz, and Robert Conners of LBNL, and Tony Lanzirotti (University of Chicago) for technical support, and John Zachara, Robert Lenhard, Steve Smith, and Bruce Bjornstad of PNNL for samples of Hanford formation sediment. We also thank Sam Ricci, Jr., and Ricci Brothers Sand Company, Port Norris, NJ for providing quartz gravel samples. Helpful internal review comments by Tim Kneafsey (LBNL) are gratefully acknowledged. This work was carried out under U.S. Dept. of Energy (DOE) Contract No. DEAC03-76SF00098, with funding provided by the DOE, Environmental Management Science Program. Research carried out (in part) at the National Synchrotron Light Source, Brookhaven National Laboratory, which is supported by the U.S. Department of Energy, Division of Materials Sciences and Division of Chemical Sciences under contract number DE-AC0298CH10886. 


\section{REFERENCES}

Brouwer, J., and H. Anderson. 2000. Water holding capacity of ironstone gravel in a typic plinthoxeralf in Southeast Australia. Soil Sci. Soc. Am. J. 64:1603-1608.

Brown, S.R., and C.H. Scholz. 1985. Broad bandwidth study of the topography of natural rock surfaces. J. Geophys. Res. 90, B14:12,575-12,582.

Brunauer, S., P.H. Emmett, and E. Teller. 1938. Adsorption of gases in multi-molecular layers. J. Am. Chem. Soc. 60:309-319.

Conca, J.L., and J. Wright. 1990. Diffusion coefficients in gravel under unsaturated conditions. Water Resour. Res. 26:1055-1066.

Conca, J.L., M.J. Apted, W. Zhou, R.C. Arthur, and J. Kessler. 1998. Flow barrier system for long-term high-level-waste isolation: Experimental results. Nucl. Technol. 124:88-99.

Dane, J.H., and J.W. Hopmans. 2002. Pressure cell. p. 684-688. In J.H. Dane and G.C. Topp (eds.) Methods of soil analysis: Part 4- Physical methods. SSSA Book Series 5. SSSA, Madison, WI.

Dane, J.H., M. Oostrom, and B.C. Missildine. 1992. An improved method for the determination of capillary pressure-saturation curves involving TCE, water, and air. J. Contam. Hydrol. 11:69-81.

Fisher, L.R., and J.N. Israelachvili. 1979. Direct experimental verification of the Kelvin equation for capillary condensation. Nature 277:548-549.

Gregg, S.J., and K.S.W. Sing. 1982. Adsorption, surface area and porosity. Academic Press, New York.

Jalbert, M., and J. H. Dane. 2001. Correcting laboratory retention curves for hydrostatic fluid distributions, Soil Sci. Soc. Am. J., 65, 648-654.

Kaplan, D. I., I. V. Kutnyakov, A. P. Gamerdinger, R. J. Serne, and K. E. Parker. 2000. Gravelcorrected Kd values. Ground Water. 38:851-857.

Khaleel, R., and J.F. Relyea. 1997. Correcting laboratory-measured moisture retention data for gravels. Water Resour. Res. 37:1567-1575.

Khaleel, R., and J.F. Relyea. 2001. Variability of Gardner's $\alpha$ for coarse-textured sediments. Water Resour. Res. 37:1567-1575.

Krumbein, W. C., and L. L. Sloss. Stratigraphy and Sedimentation, $2^{\text {nd }}$ Ed. W. H. Freeman and Co., NY, 1963.

Liu, H. H., and J. H. Dane. 1995. Improved computational procedure for retention relations of immiscible fluids using pressure cells. Soil Sci. Soc. Am. J. 59:1520-1524.

Miller, D.E., and W.C. Bunger. 1963. Moisture retention by soil with coarse layers in the profile. Soil Sci. Soc. Am. Proc. 27:586-589.

Miyazuki, T. 1988. Water flow in unsaturated soil in layered slopes. J. Hydrology 102:201-214.

Montagne, C., J. Ruddell, and H. Ferguson. 1992. Water retention of soft siltstone fragments in a Ustic torriorthent, Central Montana. Soil Sci. Soc. Am. J. 56, 555-557.

Quirk, J.P. 1955. Significance of surface areas calculated from water vapor sorption isotherms by use of the BET equation. Soil Sci. 80:423-430.

Ross, B. 1990. The diversion capacity of capillary barriers. Water Resour. Res. 26:2625-2629.

Schroth, M.H., S.J. Ahearn, J.S. Selker, and J.D. Istok. 1996. Characterization of Miller-similar silica sands for laboratory hydraulic studies. Soil Sci. Soc. Am. J. 60:1331-1339.

Selker, J. 1997. Design of interface shape for protective capillary barriers. Water Resour. Res. 33:259-260.

Sposito, G. 1984. The surface chemistry of soils. Oxford University Press, New York. 
Tokunaga, T.K., and J. Wan. 1997. Water film flow along fracture surfaces of porous rock. Water Resour. Res. 33:1287-1295.

Tokunaga, T. K., J. Wan, and S. R. Sutton. 2000. Transient film flow on rough fracture surfaces. Water Resour. Res. 36:1737-1746.

Tokunaga, T.K., J. Wan, and K.R. Olson. 2002. Saturation-matric potential relations in gravel. Water Resour. Res. 38:1214.

Wan, J., and T.K. Tokunaga. 1997. Film straining of colloids in unsaturated porous media: Conceptual model and experimental testing. Environ. Sci. Technol. 31:2413-2420.

Wan, J., and T.K. Tokunaga. 2000. Glass casts of rock fracture surfaces: A new tool for studying flow and transport. Water Resour. Res. 36:355-360.

Tables

\begin{tabular}{ccc}
\hline Salt & Relative Humidity & Water Potential \\
& & $\mathrm{MPa}$ \\
\hline $\mathrm{NaOH}$ & 0.070 & -364 \\
$\mathrm{LiCl}$ & 0.113 & -298 \\
$\mathrm{CH}_{3} \mathrm{COO}-\mathrm{K}(\mathrm{K}$-acetate $)$ & 0.200 & -220 \\
$\mathrm{CaCl}_{2}$ & 0.290 & -169 \\
$\mathrm{MgCl}_{2}$ & 0.330 & -152 \\
$\mathrm{Mg}\left(\mathrm{NO}_{3}\right)_{2}$ & 0.530 & -88 \\
$\mathrm{NaCl}$ & 0.755 & -38 \\
$\mathrm{KBr}^{\mathrm{BaCl}}$ & 0.810 & -29 \\
$\mathrm{CuSO}_{4}$ & 0.900 & -14 \\
\hline
\end{tabular}

Table 1. Saturated salt solutions used in water vapor adsorption-desorption measurements. 


\section{Figure Captions}

Fig. 1. Some possible combinations of intragranular porosity and grain surface roughness, illustrated as cross-sections through grains.

Fig. 2. Water vapor adsorption and desorption isotherms for 2 and $6 \mathrm{~mm}$ Hanford gravels, and for 2 and $9 \mathrm{~mm}$ quartz gravels.

Fig. 3. Geometry of pendular ring surface at a grain-grain contact. At low water contents $r_{1}<<r_{2}$, so that $r_{1}^{-1}>>r_{2}^{-1}$.

Fig. 4. BET plots for estimating gravel surface areas from water vapor adsorption. Surface areas determined by $\mathrm{N}_{2}$ and $\mathrm{Kr}$ adsorption are shown for comparison.

Fig. 5. Moisture retention in 2 and $6 \mathrm{~mm}$ Hanford gravels, over a wide range of matric (water) potentials. Measurement methods used are indicated along the x-axis as (a) vapor pressure regulation, (b) pressure plate, and (c) suction plate. The vapor pressure equilibration region data were obtained in adsorption mode. The suction plate and pressure plate data were obtained in drainage mode.

Fig. 6. Photographs of Hanford formation basalt gravel (a) external surface, and (b) crosssection $(\approx 300 \mu \mathrm{m}$ thick, polished slice). Note that vesicles appear as isolated circular voids in the interior region, and are pits when exposed at external surfaces.

Fig. 7. Scanning electron micrographs of a Hanford gravel surface at progressively higher magnification.

Fig. 8. Laser profiles of Hanford gravel grain surfaces.

Fig. 9. AFM images of Hanford gravel grain surfaces.

Fig. 10. Synchrotron x-ray fluorescence microprobe measurements of draining and wetting film moisture characteristics at 3 different locations (a, b, c). The spot size is about $500 \mu \mathrm{m}$ by 500 $\mu \mathrm{m}$. 


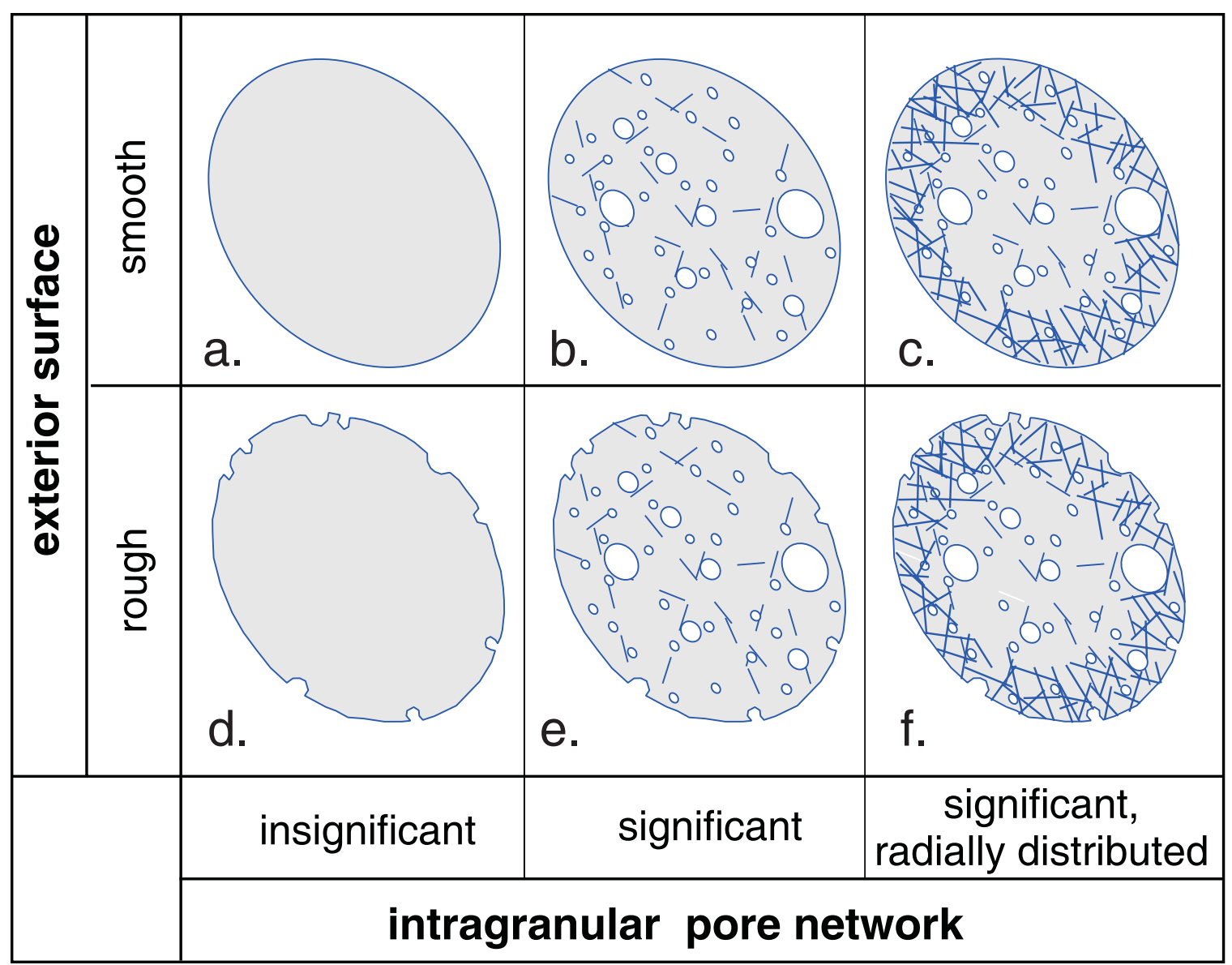

Fig. 1. Cross-section illustrations of some possible combinations of intragranular porosity and grain surface roughness. 


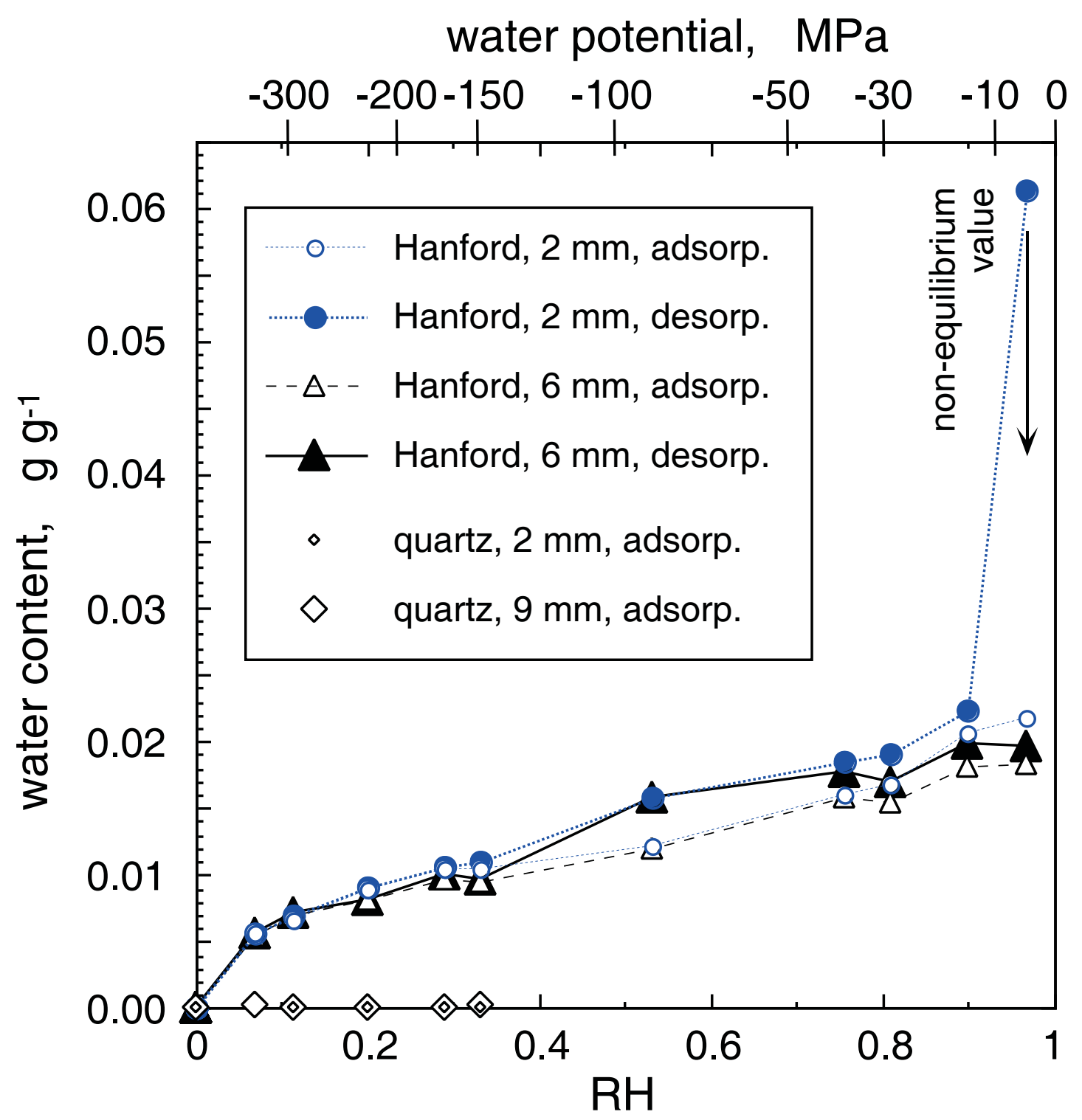

Fig. 2. Water vapor adsorption and desorption isotherms for 2 and $6 \mathrm{~mm}$ Hanford gravels, and for 2 and $9 \mathrm{~mm}$ quartz gravels. 


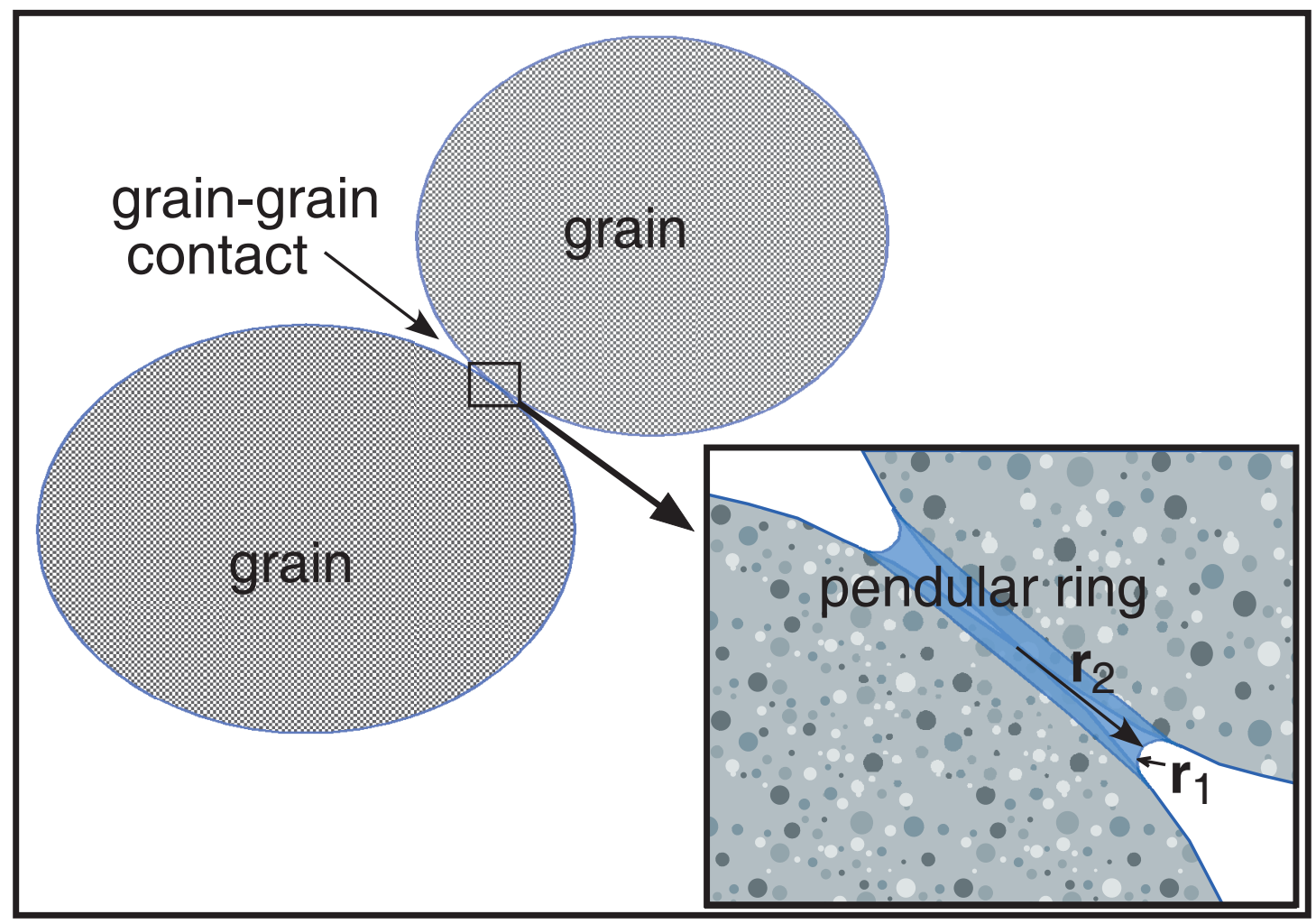

Fig. 3. Geometry of pendular ring surface at a grain-grain contact. At low water contents $\mathrm{r}_{1}<<\mathrm{r}_{2}$, so that $r_{1}^{-1}>r_{2}^{-1}$.

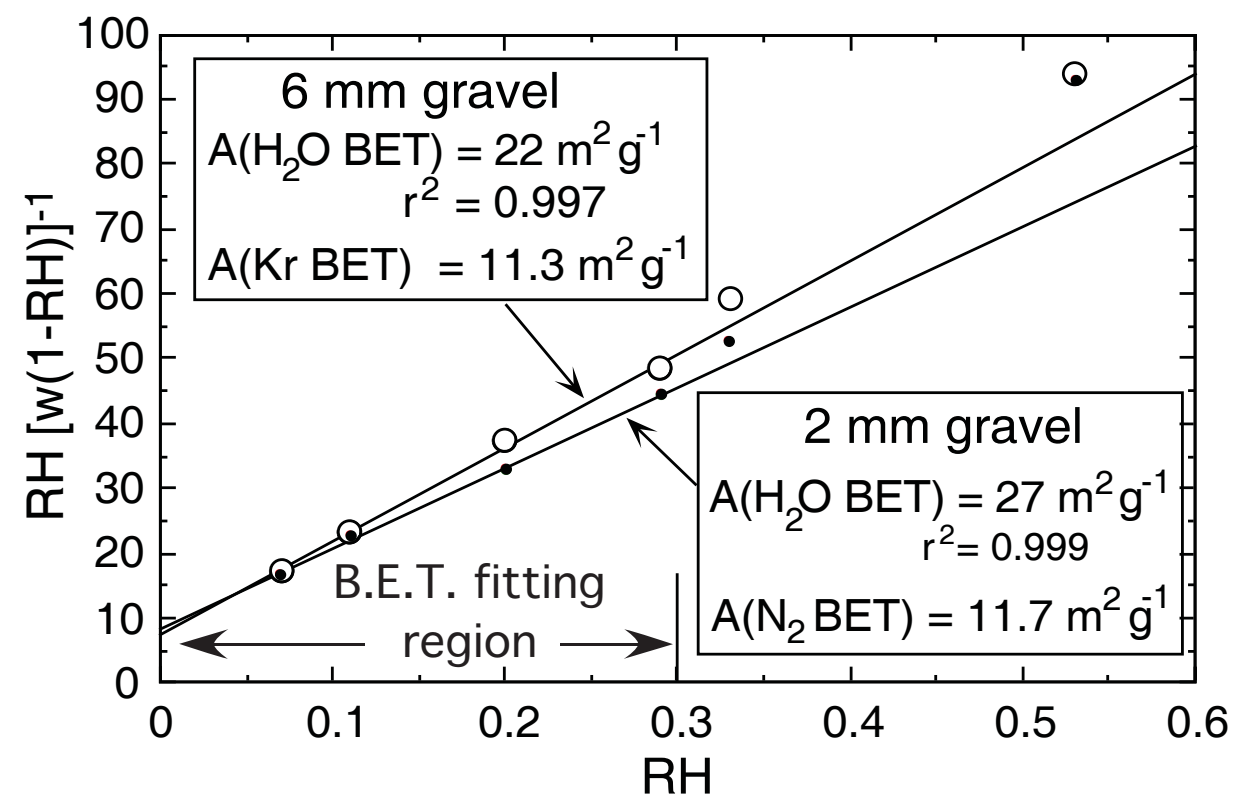

Fig. 4. BET plots for estimating gravel surface areas from water vapor adsorption. Surface areas determined by $\mathrm{N}_{2}$ and $\mathrm{Kr}$ adsorption are shown for comparison. 


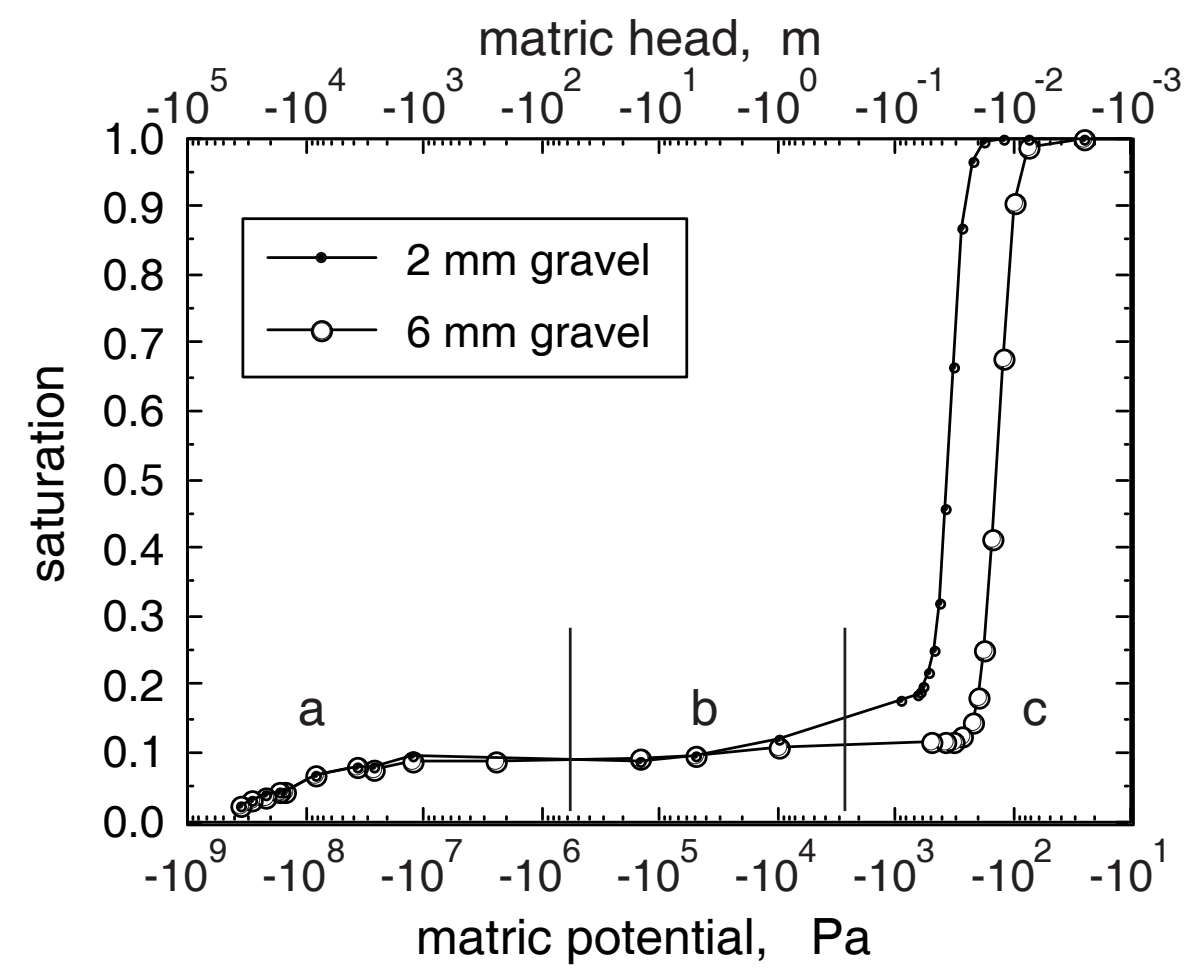

Fig. 5. Moisture retention in 2 and $6 \mathrm{~mm}$ Hanford gravels, over a wide range of matric (water) potentials. Measurement methods used are indicated along the $\mathrm{x}$-axis as (a) vapor pressure regulation, (b) pressure plate, and (c) suction plate. The vapor pressure equilibration region data were obtained in adsorption mode. The suction plate and pressure plate data were obtained in drainage mode.

冈

Fig. 6. Photographs of Hanford formation basalt gravel (a) external surface, and (b) crosssection $(\approx 300 \mu \mathrm{m}$ thick, polished slice). Note that vesicles appear as isolated circular voids in the interior region, and are pits when exposed at external surfaces. 


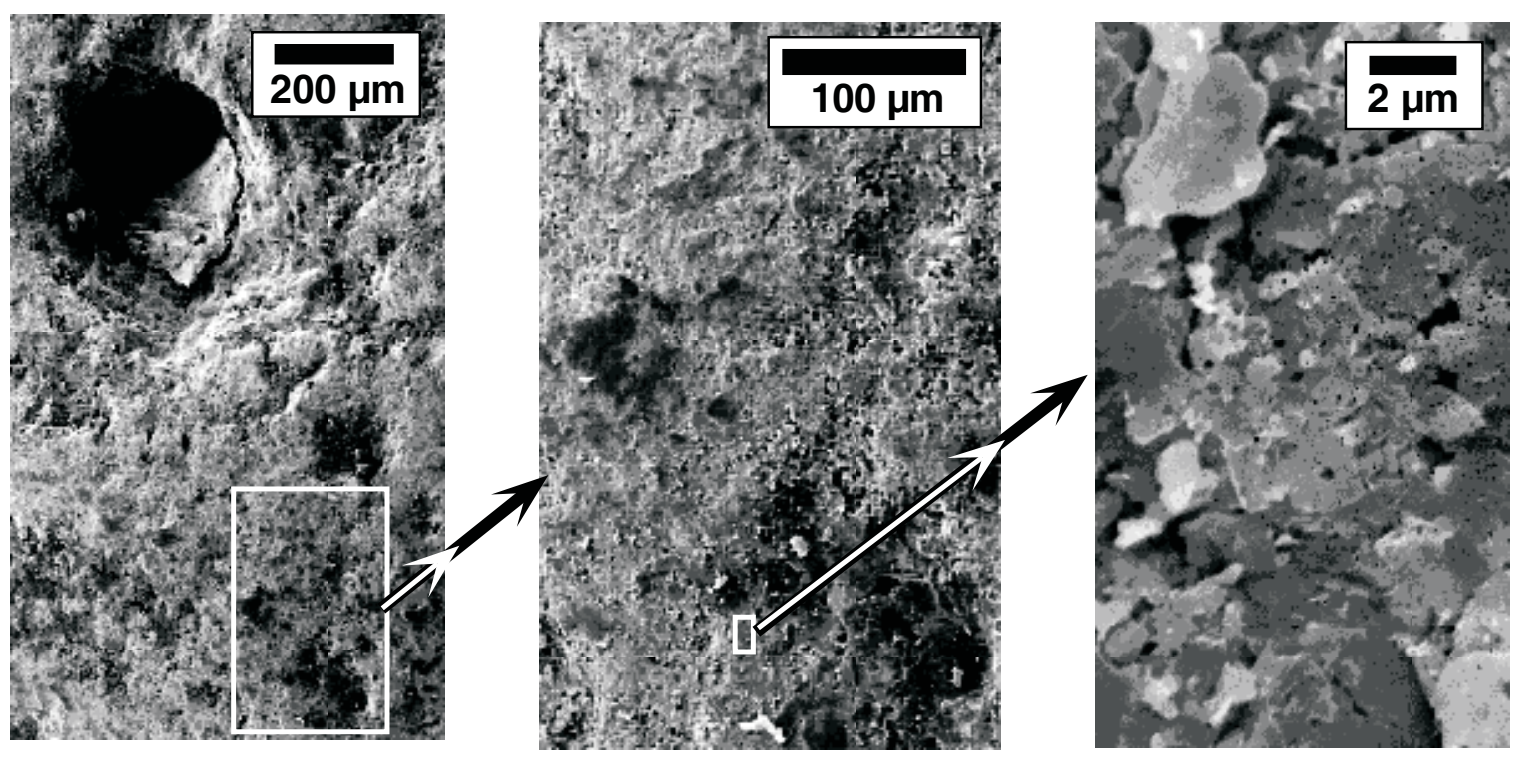

Fig. 7. Scanning electron micrographs of a Hanford gravel surface at progressively higher magnification.

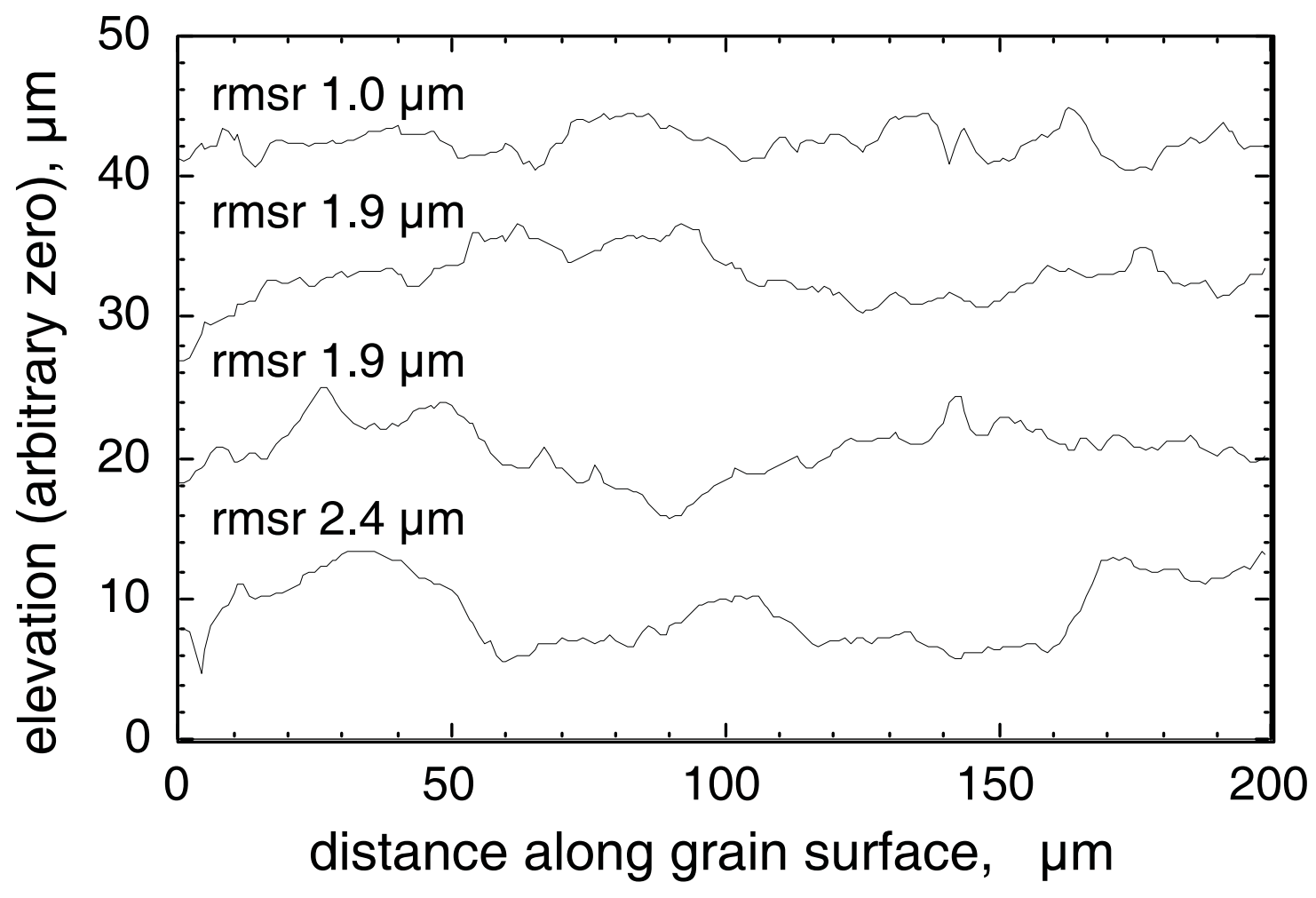

Fig. 8. Laser profiles of Hanford gravel grain surfaces. 


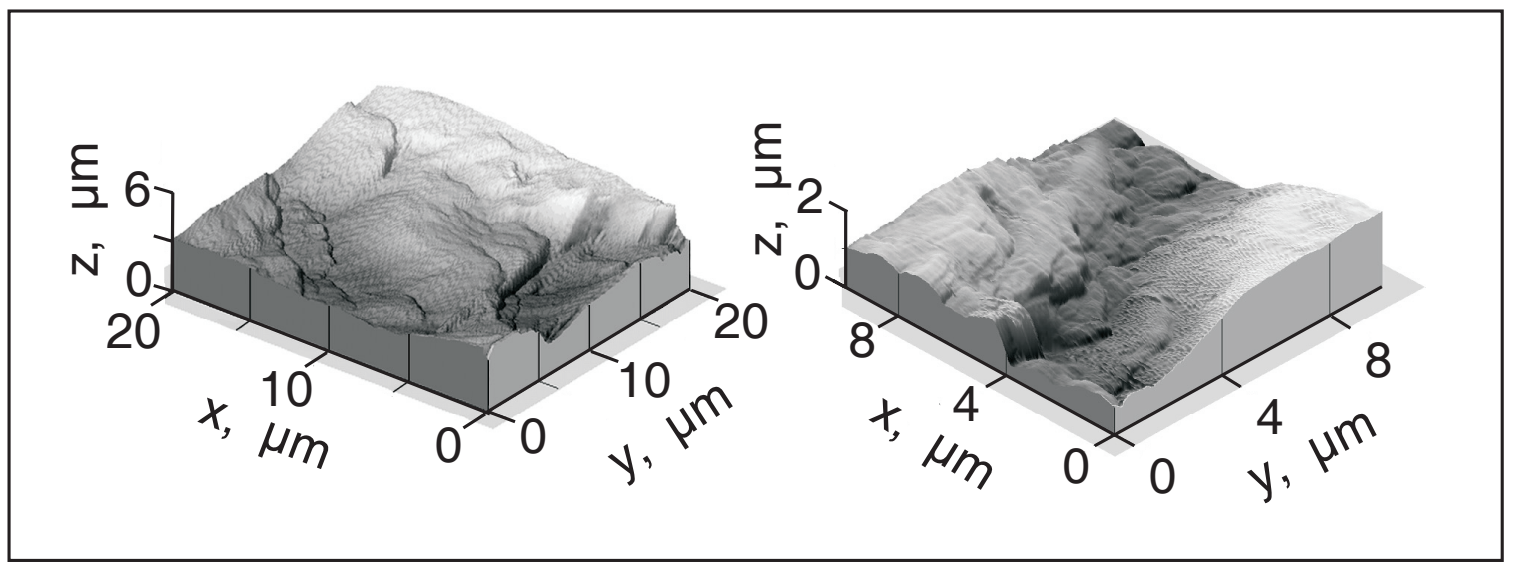

Fig. 9. AFM images of Hanford gravel grain surfaces. 

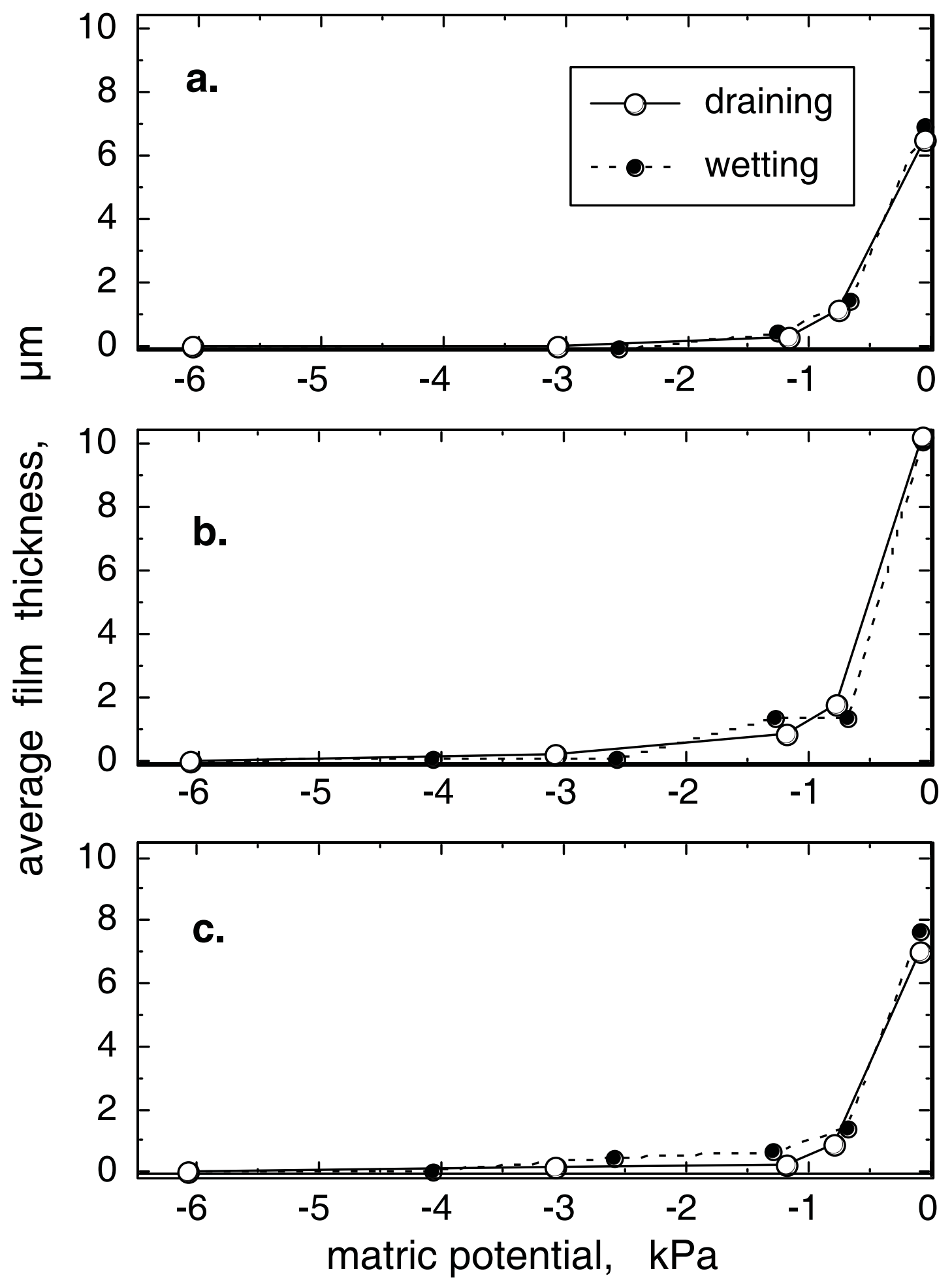

Fig. 10. Synchrotron x-ray fluorescence microprobe measurements of draining and wetting film moisture characteristics at 3 different locations (a, b, c). The spot size is about $500 \mu \mathrm{m}$ by 500 $\mu \mathrm{m}$. 